Hydrology and Earth System Sciences, 8(3), 560-566 (2004) C $\quad$ EGU

\title{
Leaf transport and retention in a high gradient stream
}

\author{
James L. Pretty ${ }^{*}$ and Michael Dobson \\ Department of Environmental and Geographical Sciences, Manchester Metropolitan University, Chester Street, Manchester M1 5GD, UK \\ "Present address: School of Biological Sciences, Queen Mary University of London, Mile End Road, London E1 4NS, UK
}

Email for corresponding author: j.1.pretty@qmul.ac.uk

\begin{abstract}
To a large extent, the invertebrate fauna in wooded streams rely upon detritus inputs from the surrounding vegetation as their main food source. Conifer plantations may alter the timing and nutritional quality of leaf inputs into streams, but detritus retention may also be reduced. While it has often been assumed that conifer needles are retained less than broadleaved species, this has never been tested experimentally. This study describes the results of a leaf release experiment carried out in a small headwater stream, comparing the retention of pine needles and oak leaves (wet and dry) over a range of discharges. In addition, retention was compared before and after placing logs in the stream to examine the effect of woody debris on retention efficiency. Retention efficiency was significantly different among the three leaf types tested with wet oak leaves being most retentive, followed by dry oak leaves with dry pine needles being least retentive. Retention efficiency declined significantly with increasing discharge for all three leaf types. The addition of logs increased the retention of dry oak leaves and pine needles, but not wet oak leaves. The predominant features (stones, logs, eddies and bankside vegetation) that accounted for retention varied with discharge and the leaf type used. The results indicate that while conifer needles may be inherently less retentive than broadleaves, the presence of woody debris within the stream channel increases their retention. However, this small-scale study would need to be expanded to investigate the retention dynamics of conifer needles in plantation streams. Nevertheless, management strategies that allow the formation of woody debris accumulations in plantation streams could be valuable in enhancing detritus retention and consequently could benefit invertebrate communities.
\end{abstract}

Keywords: pine needles, retention efficiency, woody debris, discharge

\section{Introduction}

The invertebrate fauna of wooded streams rely primarily upon allochthonous inputs of detritus from the surrounding vegetation as an energy source (Fisher and Likens, 1973; Cummins, 1974). Wooded streams may receive a large amount of organic matter from terrestrial sources (Webster and Meyer, 1997) but this material can be colonised and consumed only by the microbial and invertebrate fauna if it becomes retained upon the stream bed. The process of retention, therefore, provides a crucial link between the primary consumers in the stream food web and their main food source. Effective retention is an important factor in maintaining high secondary production and the cycling of key nutrients in the forest-stream ecosystem (Allan, 1995).

The retention efficiency of a stream is influenced strongly by hydrological characteristics of a stream. For example,
Snaddon et al. (1992) found that, regardless of stream morphology, leaf retention decreased with increasing stream discharge. In addition, the channel substrata and structures that increase the channel roughness, such as rocks, cobbles and woody debris, greatly increase the retentive capacity of a stream (Webster et al., 1994). In contrast, streams with a lower wetted perimeter to cross-sectional area ratio have much lower detritus retention (Speaker et al., 1984). Dead wood (DW) is probably the single most important retention device within a stream; branches and twigs trap passing detritus as well as creating areas of low flow where organic matter can settle, further enhancing the retention process (Trotter, 1990). Retention is therefore greatest in areas with large amounts of DW (Ehrman and Lamberti, 1992; Pretty and Dobson, 2004)

Among the various impacts of commercial forestry on 
streams is its influence on basal energy resources. Conifer needles are of poor nutritional quality (Iversen, 1974; Friberg and Jacobsen, 1994) due to their chemical content and the fact that they inhibit the colonisation of bacteria and fungi, which increase the palatability of leaves for invertebrate detritivores (Sedell et al., 1975; Bärlocher et al., 1978). Therefore, the productivity of streams running through conifer plantations can be reduced relative to those in broadleaved woodland (Friberg et al., 2002). However, even conifer needles become palatable to invertebrate detritivores if retained on the stream bed for long enough to allow significant microbial conditioning, so the extent to which they are retained is important. This, in turn, is a function of stream channel characteristics, flow regime and the leaf structure.

Studies comparing the relative retentive efficiency of different leaf species are somewhat limited, but the retention potential of an individual leaf is determined by its size and shape, and also whether it is wet or dry when it enters the channel. Young et al. (1978) determined that leaf size was the most important factor among dry leaves of beech (Fagus grandifolia Ehrh.), red oak (Quercus rubra L.) and red maple (Acer rubrum L.), with large leaves becoming more easily retained. When wet, large leaves travelled furthest and retention efficiency was more related to leaf flexibility. Similarly, Prochazka et al. (1991) found retention to be higher for flexible red elm (Cunonia capensis L.) leaves compared to the stiff leaves of wild almond (Brabejum stellatifolium L.).

Conifer needles are generally both small and inflexible compared with broadleaved species, and as such, their retention can be assumed to be lower. However, the practical difficulties of field investigations using conifer needles mean that this has not been tested. Therefore, the aim of the study was to determine the retention of conifer needles, and to compare it with that of broadleaves, in a high-gradient forested stream. Trials were carried out before and after logs were added to the stream stretch to assess the effect of DW on retention.

Most studies of retention follow the method outlined by Lamberti and Gregory (1996); whereby a known number of identifiable leaves is released at the top of a study stretch of stream and their position mapped through time. Various techniques have been used to make the released leaves distinguishable from 'natural' leaves, including marking the leaves with dye or paint (Jones and Smock, 1991; Chergui et al., 1993), using artificial replacements such as plastic strips or wooden dowels (Speaker et al., 1988; Webster et al., 1994), or using a leaf species absent from the study site (Ehrman and Lamberti, 1992). An alternative method is to release leaves individually and then to follow them until they are retained or reach the end of the study reach. Although this method has been employed in the past (e.g. Hildrew et al., 1991), it is rarely used because of the time required to release enough replicates and because of the difficulty in following individual leaves, particularly if they are unmarked. However, it is the most practical method for leaves of small size that will be difficult to find once released, such as conifer needles, and so was the method used here.

\section{Methods}

Stake Clough $\left(53^{\circ} 15^{\prime} \mathrm{N}, 1^{\circ} 59^{\prime} \mathrm{W}\right)$ is a permanently acid second order stream in the Derbyshire Peak District of England. It rises at an altitude of around $500 \mathrm{~m}$ and flows through peat moorland before entering mixed woodland, which at the study reach is dominated by oak (Quercus robur L.), European larch (Larix decidua Mill.) and Scots pine (Pinus sylvestris L.). Stake Clough contains very few areas where large amounts of detritus can accumulate and is regarded as being poorly retentive of organic matter (Cariss and Dobson, 1997). The study was carried out in an $8 \mathrm{~m}$ reach where the channel was straight and consisted of a series of riffles and shallow glides (depth $<30 \mathrm{~cm}$ ); it had a mean width of $1.8 \mathrm{~m}( \pm 20 \mathrm{~cm})$, a slope of $4.35 \%$ and an unstable substrate consisting of shale and flat stones.

The study was carried out using leaves of oak and Scots pine, collected from the study site, air-dried and stored in plastic bags until use. The experiment was conducted using dry oak leaves, wet oak leaves (previously dried leaves that had been soaked in tap water for around $12 \mathrm{~h}$ prior to use) and dry pine needles. To increase their visibility, pine needles were sprayed with bright pink paint, which did not influence their buoyancy relative to unsprayed leaves over the short periods of time (up to 15 minutes) required for this study. Wetted needles were not used because they could not be seen as they flowed downstream. In all cases, complete 'double needles' were used to avoid potential differences between double and single needles.

Forty oak leaves (20 dry, 20 soaked) and 20 pine needles were used in each trial. Each leaf was released individually in a random order at the top of the study stretch and the time taken to reach the $8 \mathrm{~m}$ mark was recorded. If leaves became trapped for over 1 minute, the distance travelled and the retention feature (streambed, bank or eddy) were recorded. After this had been completed, three logs $(1 \mathrm{~m}$ long, $0.1 \mathrm{~m}$ diameter) were added to the downstream half of the stretch at 5,6 and $7 \mathrm{~m}$. The leaf releases were then repeated as before, this time making additional notes when leaves became retained against the logs. The entire study was repeated on six different occasions between February 1999 and April 2000 at different levels of discharge, 
although it was impossible to use pine needles on one of these occasions due to high turbidity.

Differences in the proportion of leaves retained among the three leaf types on each occasion were assessed using two-way ANCOVA, with leaf type and manipulation as factors and discharge as the covariate. Retention efficiency was compared for each leaf type separately using scatter plots. Simple linear regression was carried out on each to test whether there was a significant relationship between retention and stream discharge. For each leaf type, the regression lines were compared using the $t$-tests outlined by Zar (1984). This enabled the slope and elevation of each line to be compared before and after addition of logs. Leaf proportions were arcsin transformed before running analyses.

\section{Results}

Dry oak leaves and pine needles tended to float on the stream surface, whilst wet oak leaves tended to travel within the water column. There was a significant difference in proportion of leaves retained among the three leaf types (Table 1), with wet oak leaves being the most retentive leaf type used. The addition of logs tended to increase retention, a phenomenon most marked for dry oak leaves (Fig. 1). The effect of log addition was, however, greater for pine needles than for wet oak, despite needles being less retentive than both wet and dry oak leaves (Fig. 1); indeed, log addition did not greatly enhance retention of wet oak leaves (Fig. 1b).

The retention efficiency of all leaf types decreased with increasing stream discharge, regardless of whether logs were added to the stream channel (Fig. 1). This relationship was significant for all leaf types (Fig. 1, Table 2), except needles after $\log$ addition, although this was almost significant. Each leaf type showed a similar pattern and the regression lines before and after log addition did not significantly differ in slope (student's $t$-test $P>0.05$, in all cases).
Table 2. Summary of the Simple Linear Regression between stream discharge and leaf retention, both before and after the addition of DW. Significance levels: $* P<0.05 ; * * P<0.01 ; * * * P<0.001$; NS not significant.

\begin{tabular}{lcll}
\hline & $F$-ratio & $P$ & $R_{2}$ \\
\hline Dry Oak Leaves & & & \\
Before manipulation & 38.79 & $* *$ & 0.89 \\
After manipulation & 19.53 & $*$ & 0.83 \\
Wet Oak Leaves & & & \\
Before manipulation & 90.65 & $* * *$ & 0.95 \\
After manipulation & 27.54 & $* *$ & 0.87 \\
& & & \\
Pine Needles & & & \\
Before manipulation & 22.83 & $*$ & 0.88 \\
After manipulation & 9.86 & NS & 0.77 \\
\hline
\end{tabular}

The features that accounted for retention varied with discharge and the leaf type used (Fig. 2). Both dry oak leaves and pine needles were commonly caught in eddies at low discharge, but less so as discharge increased. Conversely, wet oak leaves were rarely caught in eddies at any discharge. At low discharges, similar numbers of dry and wet oak leaves were retained by stones on the streambed, whereas at higher flows, wet oak leaves tended to be caught more consistently on stones than the dry oak leaves, while pine needles were rarely caught on the stone substrate at any discharge (Fig. 2 ). Retention of oak leaves on the added logs showed a similar pattern to that of the stone retention, with similar numbers being retained at low discharge but more wet oak being caught at higher flows, and they caught relatively few needles at all but the lowest discharges.

\section{Discussion}

Conifer needles have often been assumed to be less retentive than broadleaves but practical difficulties in using needles

Table 1. ANCOVA table, showing the influence of leaf type and stream channel manipulation on proportion of leaves retained, under different flow regimes. ${ }^{*} P<0.05 ; * * P<0.01 ; * * * P<0.001$; NS not significant.

\begin{tabular}{lccccc}
\hline Source & Sum-of-squares & $d f$ & Mean-square & F-ratio & $P$ \\
\hline Leaf type & 0.729 & 2 & 0.365 & 7.322 & $* *$ \\
Manipulation & 0.599 & 1 & 0.599 & 12.023 & $* *$ \\
Leaf type x Manipulation & 0.070 & 2 & 0.035 & 0.701 & NS \\
Discharge & 4.176 & 1 & 4.176 & 83.818 & $* * *$ \\
Error & 1.345 & 27 & 0.050 & & \\
\hline
\end{tabular}



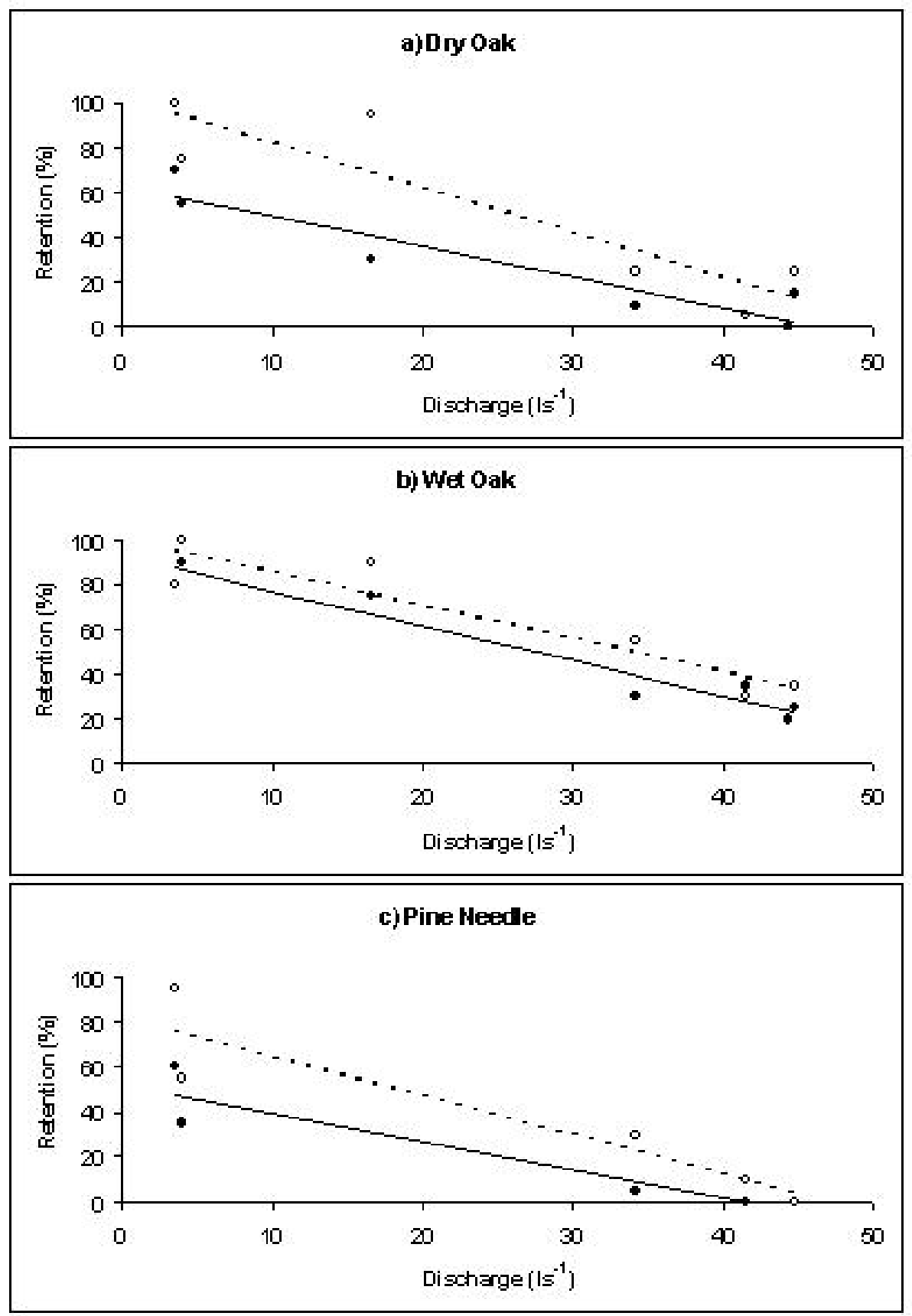

Fig. 1. Retention efficiency (percentage of each leaf type retained within the experimental reach) of released leaves over a range of discharges, before log addition (black symbols, solid line) and after log addition (open symbols, broken line).

have discouraged their use in experiments. The pine needles used in this study were less retentive than either dry or soaked oak leaves. This finding is not surprising because pine needles are small, lightweight, inflexible and streamlined. Similar findings have been reported for stiff elongated Nerium oleander L. leaves (Chergui et al., 1993) and the inflexible leaves of Brabejum stellatifolium L.
(Prochazka et al., 1991). The pink paint used to mark the needles may have modified their flow pattern, but laboratory comparisons of painted and unpainted needles give us confidence that any effect would be negligible. Due to the waxy cuticle of pine needles, the paint probably did not greatly alter texture or flexibility, and its effect on buoyancy was assumed to be small. This is the first time conifer needles 
a) $35 \mathrm{ss}^{-1}$

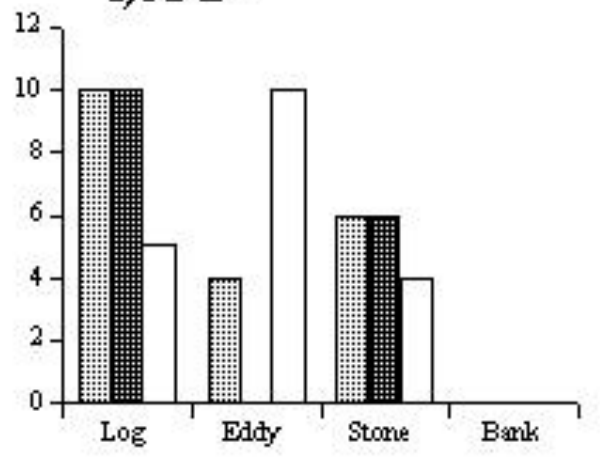

b) $4.0 \mathrm{ls}^{-1}$

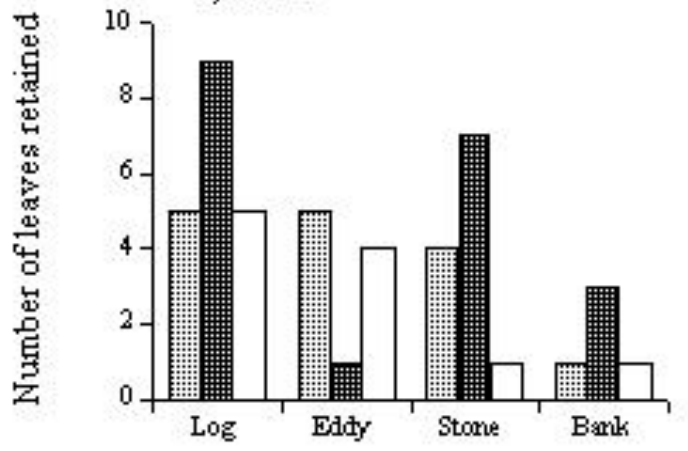

c) $15.6 \mathrm{ls}^{-1}$

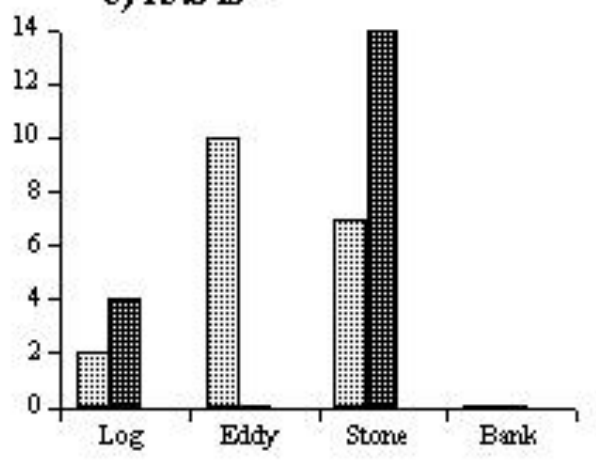

d) $34.1 \mathrm{ls}^{-1}$

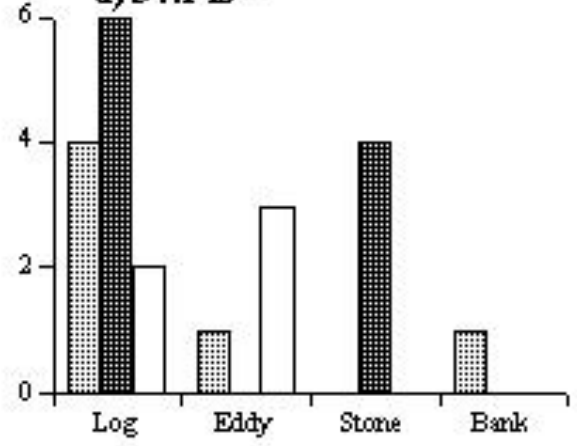

e) $415 \mathrm{ks}^{-1}$

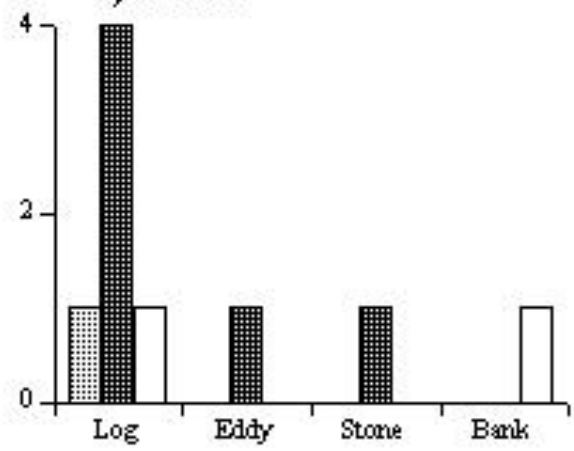

f) $44.7 \mathrm{ls}^{-1}$

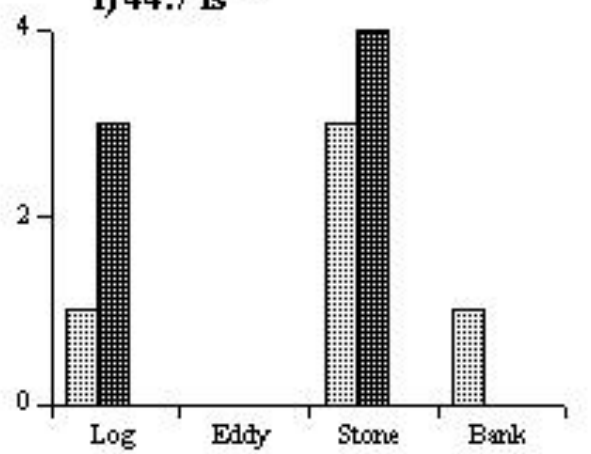

dy osk $\quad$ 粬 wet osk $\square$ pine needle

Fig. 2. Number of leaves retained by each retention feature at different discharges. Note that no needle data was available for 15.6 l $s^{-1}$ (Fig. 2c). NB. Different scales y-axes.

have been used in a leaf release experiment and provides empirical evidence to support previous assumptions about their poorly retentive nature.

Many pine needles were retained on short-term retention devices such as eddies and bankside vegetation, especially at low flows, when retention potential was at its highest. In this study, a time period of just one minute was taken to constitute 'retention' and it is highly likely that most of these needles would be washed away when discharge increased. Considering that conifer needles require long retention times to allow microbial conditioning, such short-term retention would be of little benefit to invertebrate detritivores. Furthermore, leaves floating in an eddy or caught against trailing vegetation may be of little use to the stream benthos 
because colonisation would be difficult. Nevertheless, even temporary retention devices may be important by allowing needles to become soaked and thus more likely to be retained for longer periods in the future. Furthermore, eddies may be important sites for microbial conditioning, especially where foam accumulates, as it is laden with the spores of aquatic hyphomycetes (E. Chauvet, pers. comm.).

Wet oak leaves were retained most effectively, supporting findings by Young et al. (1978) who found the average distance travelled by soaked leaves was less than dry leaves. This can be attributed to two main factors. Firstly, soaked leaves were more flexible than dry leaves and more easily snagged against obstacles. Secondly, soaked leaves were approximately neutrally buoyant and travelled within the water column rather than the stream surface. This increased their likelihood of encountering obstacles such as stones on the streambed.

Unfortunately, only dry needles could be monitored in this study and it is possible that wet needles would be more retentive. Soaked needles did sink below the stream surface (Pers. Obs.) and it is likely that wet needles would be retained for longer periods against stones and wood on the streambed. This idea is supported by the difference between wet and dry oak leaves. Dry oak leaves were often caught on temporary retention devices like eddies and trailing bankside vegetation, whereas wet oak leaves tended to miss these features and get caught on stones.

These results do not allow an accurate estimation of stream retentive capacity, which has been the objective of most previous leaf release experiments. Lamberti and Gregory (1996) recommend a stream reach at least ten times the stream width, so the $8 \mathrm{~m}$ stretch used at Stake Clough was probably inadequate to be truly representative of the stream. Most previous leaf release experiments have used a stretch between 50 and $150 \mathrm{~m}$, but have generally taken place in larger streams (e.g. Young et al., 1978; Ehrman and Lamberti, 1992). Despite the different methodological approach taken in this study, however, the results support the general findings from previous studies. The reduced retention efficiency at higher discharge has been well documented (Jones and Smock, 1991; Snaddon et al., 1992) and in this study, even moderate increases in flow greatly reduced the number of leaves retained. Considering that a discharge of around $45 \mathrm{l} \mathrm{s}^{-1}$ was sufficient to reduce retention significantly, and the maximum discharge recorded at Stake Clough was over $2001 \mathrm{~s}^{-1}$, it is easy to see why detritus storage is low.

In terms of forestry management, these results suggest that whilst the timing, nutritional value and diversity of leaf inputs are altered in plantation streams (Pozo et al., 1997; Murphy and Giller, 2000), leaf retention may also be reduced. Sitka spruce (Picea sitchensis (Bong.) Carr.) is the dominant plantation species used in Britain, and the small needles of this species are probably even less retentive than the poorly retained pine needles used in this study. The low retentive potential of such leaves is certainly exacerbated by the lack of DW in streams impacted by commercial forestry.

\section{Acknowledgements}

The authors thank the Forestry Commission for allowing access to the field site.

\section{References}

Allan, J.D., 1995. Stream Ecology: Structure and Function of Running Waters. Chapman and Hall, London, UK.

Bärlocher, F., Kendrick, B. and Michaelides, J., 1978. Colonisation and conditioning of Pinus resinosa needles by aquatic hyphomycetes. Arch. Hydrobiol., 81, 462-474.

Cariss, H. and Dobson, M., 1997. Transport and retention of detritus in upland streams: a comparison of an open stream and an adjacent wooded site. Limnetica, 13, 85-91.

Chergui, H., Maamri, A. and Pattee, E., 1993. Leaf litter retention in two reaches of a Moroccan stream. Limnologica, 23, 29-37.

Cummins, K.W., 1974. Structure and function of stream ecosystems. Bioscience, 24, 631-641.

Ehrman, T.P. and Lamberti, G.A., 1992. Hydraulic and particulate matter retention in a third order Indiana stream. J. N. Amer. Benthol. Soc., 11, 341-349.

Fisher, S.G. and Likens, G.E., 1973. Energy flow in Bear Brook, New Hampshire: an integrative approach to stream ecosystem metabolism. Ecol. Monogr., 43, 421-439.

Friberg, N. and Jacobsen, D., 1994. Feeding plasticity of two detritivore shredders. Freshwater Biol., 32, 133-142.

Friberg, N., Larsen, A.D., Rodkjaer, A. and Thomsen, A.G., 2002. Shredder guilds in three Danish forest streams contrasting in forest type. Arch. Hydrobiol., 153, 197-215.

Hildrew, A.G., Dobson, M., Groom, A., Ibbotson, A., Lancaster, J. and Rundle, S.D., 1991. Flow and retention in the ecology of stream invertebrates. Verh. Internat. Verein. Limnol., 24, 17421747.

Iversen, T.M., 1974. Ingestion and growth in Sericostoma personatum (Trichoptera) in relation to the nitrogen content of ingested leaves. Oikos, 25, 278-282.

Jones, J.B. and Smock, L.A., 1991. Transport and retention of particulate organic matter in two low-gradient headwater streams. J. N. Amer. Benthol. Soc., 10, 115-126.

Lamberti, G.A. and Gregory, S.V., 1996. Transport and retention of CPOM. In: Methods in Stream Ecology, F.R. Hauer and G.A. Lamberti (Eds.), Academic Press, San Diego, California, USA. 217-229.

Murphy, J.F. and Giller, P.S., 2000. Detrital inputs to two loworder streams differing in riparian vegetation. Verh. Internat. Verein. Limnol., 27, 1351-1356.

Pozo, J., Gonzalez, D., Diez, J.R., Molinero, J and Elosegui, A., 1997. Inputs of particulate organic matter to streams with different riparian vegetation. J. N. Amer. Benthol. Soc., 16, 602611.

Pretty, J.L. and Dobson, M. 2004. The response of macroinvertebrates to artificially enhanced detritus levels in plantation streams. Hydrol. Earth Syst.Sci., 8, 550-559. 
Prochazka, K., Stewart, B.A. and Davies, B.R., 1991. Leaf litter retention and its implications for shredder distribution in two headwater streams. Arch. Hydrobiol., 120, 315-325.

Sedell, J.R., Triska, F.J. and Triska, N.S., 1975. The processing of conifer and hardwood leaves in two coniferous forest streams: I. weight loss and associated invertebrates. Verh. Internat. Verein. Limnol., 19, 1617-1627.

Snaddon, C.D., Stewart, B.A. and Davies, B.R., 1992. The effect of discharge on leaf retention in two headwater streams. Arch. Hydrobiol., 125, 109-120.

Speaker, R.W., Luctessa, K.J. and Franklin, J.F. 1988. The use of plastic strips to measure leaf retention by riparian vegetation in a coastal Oregon stream. Amer. Midland Naturlist, 120, 22-31.

Speaker, R.W., Moore, K. and Gregory, S., 1984. Analysis of the process of retention of organic matter in stream ecosystems. Verh. Internat. Verein. Limnol., 22, 1835-1841.
Trotter, E.H., 1990. Woody debris, forest-stream succession and catchment geomorphology. J. N. Amer. Benthol. Soc., 9, 141156.

Webster, J.R. and Meyer, J.L., 1997. Stream organic matter budgets - introduction. J. N. Amer. Benthol. Soc., 16, 5-13.

Webster, J.R., Covich, A.P., Tank, J.L. and Crockett, T.V., 1994. Retention of coarse organic particles in the southern Appalachian Mountains. J. N. Amer. Benthol. Soc., 13, 140-150.

Young, S.A., Kovalak, W.P. and Del Signore, K.A., 1978. Distances travelled by autumn shed leaves introduced into a woodland stream. Amer. Midland Naturalist, 100, 217-222.

Zar, J.H. 1984. Biostatistical Analysis. Second Edition. Prentice Hall, New Jersey, USA. 